\title{
Dendritic magnetite crystals in rapid quenched fine spherules produced by falling experiments through the high temperature furnace with controlled gas flow
}

\author{
Hiroshi IsoBE and Takaaki GoNDo \\ Department of Earth and Environmental Sciences, School of Science, \\ Graduate School of Science and Technology, Kumamoto University, \\ 2-39-1 Kurokami, Chuo-ku, Kumamoto 860-8555, Japan
}

\begin{abstract}
Magnetite is a common accessory mineral in various rocks. Crystal shapes and habits of magnetite show diversity depending on crystallization conditions, especially cooling rate. Characteristic dendritic or skeletal magnetite crystals occur in quench rims of effusive rocks. The dendritic magnetite also occur in micrometeorites undergone quick heating and quenching at atmospheric entry. In this study, we constructed a fine particle free fall apparatus in a high temperature furnace to carry out crystallization experiments with controlled rapid heating and quenching. Experiments were carried out in a high-temperature vertical tube furnace with $\mathrm{H}_{2}, \mathrm{CO}_{2}$ and $\mathrm{Ar}$ mass flow controllers to control oxygen partial pressure and total gas flow rate. At the top of the furnace, a silica glass tube with an orifice with approximately $0.5 \mathrm{~mm}$ in diameter was set to keep falling rate of particles. Particles were retrieved in an alumina crucible at the bottom of the furnace tube. Terminal velocity of silicate particles with $100 \mu \mathrm{m}$ in diameter in the static Ar gas at $1200{ }^{\circ} \mathrm{C}$ is approximately $0.18 \mathrm{~m} / \mathrm{s}$. Gas ascent rate at 1200 ${ }^{\circ} \mathrm{C}$ is approximately $0.11 \mathrm{~m} / \mathrm{s}$ in the furnace tube when gas flow rate is approximately $1 \mathrm{l} / \mathrm{min}$ at standard condition. The falling velocity of the particles with $100 \mu \mathrm{m}$ in diameter, therefore, is reduced to approximately 0.07 $\mathrm{m} / \mathrm{s}$. When the highest temperature in the furnace tube set to $1520^{\circ} \mathrm{C}$, the falling particles reach $1400{ }^{\circ} \mathrm{C}$ within $2 \mathrm{~s}$, keep above $1400^{\circ} \mathrm{C}$ more than $1 \mathrm{~s}$, and are quenched within $1 \mathrm{~s}$. For the fine particles with $100 \mu \mathrm{m}$ in diameter, time scale of thermal equilibrium by radiation can be achieved within $0.1 \mathrm{~s}$. In the experiments with volcanic ash particles, we found quite characteristic dendritic magnetite crystals in rapid-quenched spherules. From particles with high volume fraction of magnetite, we can see quite characteristic texture in which dendritic magnetite cover almost whole surface of the spherule. Magnetite dendrite crystals with particular crystallographic orientation also occur. The rapid quenching experiments for fine particles can be applied to reproduce atmospheric entry heating processes of micrometeorites.
\end{abstract}

Keywords: Magnetite, Dendrite, Rapid quench, Spherule, Micrometeorite

\section{INTRODUCTION}

Magnetite is one of the quite common accessory minerals occurred in various rocks. Habit, crystal size and textures of magnetite are mostly controlled by thermal history at the crystallization and chemical composition of the crystallization system. Euhedral magnetite crystals commonly occur as a high temperature liquidus mineral in quenched glass fraction from silicate melt phases. Especially, characteristic dendritic and skeletal magnetite crystals represent quite rapid cooling rate from the silicate melt at nu-

doi:10.2465/jmps. 121101

H. Isobe, isobe@sci.kumamoto-u.ac.jp Corresponding author cleation and crystal growth steps in the crystallization. Rapid quenched products from high temperature silicate melts can be seen in the results of vigorous, short term processes including pyroclastic fall deposits, effusive rocks at seafloor, fulgurites and micrometeorites heated at atmospheric entry. Dendritic or skeletal magnetite crystals with various shape, habit, size and texture are found as a typical accessory mineral in the rapid quenched melt.

The most typical dendritic magnetite crystals as quench crystals occur in the quench clasts of basaltic effusive rocks (e.g., Szramek et al., 2010). In the core of the basaltic pumice clast, randomly oriented magnetite microlites more than $20 \mu \mathrm{m}$ in length crystallized during cooling processes at the eruption. A great variety of iron oxide 
minerals in igneous rocks including skeletal morphologies are presented by Haggerty (1991). Skeltal Fe-Ti oxide minerals occur in quenched dike and roof zone of the magma chamber (e.g., Rice et al., 1971; Naslund, 1984). These crystals grow up to several millimeters in length depending on cooling rate of the magma. Skeletal magnetite crystals are also found in Martian meteorite (Sautter et al., 2002).

More rapid quenching products from high temperature silicate melts can be seen in fulgurites which are momentary fused by lightning strikes (Grapes and MullerSigmund, 2010). In the extraordinary rapid quenched rim of the fulgurites, magnetite dendrites from several to 20 $\mu \mathrm{m}$ in length occurred with latticework texture of magnetite crystal needles.

Dendritic magnetite crystals also occur in igneous rim of micrometeorites (e.g., Genge, 2006, 2008). Micrometeorites are derived from fine particles of interplanetary materials continuously falling onto the Earth. Typical size of the interplanetary particles around the Earth is $200 \mu \mathrm{m}$ in diameter (Love and Brownlee, 1993). Meteorites are planetary materials survived an atmospheric heating because of its size before the entry. Meteor particles have several millimeters in diameter before the entry and heated to high temperature enough to emit bright light and to vaporize completely at the upper atmosphere. Micrometeorites are much smaller than meteor particles and mildly lose their kinetic energies. Micrometeorites are recovered from the polar ice or oceanic sediment and consist of melted and quenched part and relict materials with various proportions due to their thermal histories depending on their size and velocity. Texture and composition of the micrometeorites, especially quench crystals including magnetite and olivine dendrites in quenched melt phase, can provide information not only on the atmospheric entry conditions but also original characteristics of the micrometeorites related to the origin of the solar system.

Spinel dendrite crystals occur in the run products by heating experiments of meteorite fragments to reproduce micrometeorites (Toppani et al., 2001, Toppani and Libourel, 2003). Fine particles including framboidal magnetite (Fayek et al., 2012), iron oxide crystals in spherical melt particles (Mirsa et al., 2009), magnetite spherules in tektite (Kleinmann, 1969) or sediment close to PermianTriassic and Cretaceous-Tertiary boundaries (Korchagin et al., 2010; Robin et al., 1996) are also reported. Natural iron oxide minerals show diverse size, crystal habits and textures depending on formation processes, especially cooling history from high temperature conditions. Artificial iron oxide crystals are synthesized to understand oxidation state of iron and microscale processes in the crystal structures (Longo et al., 2011) and to investigate physical properties of magnetite nanoparticles (Woltz et al., 2006). The most important parameter to control the textures of synthesized iron oxide crystals is a cooling rate at the very beginning of the crystallization processes.

To achieve accurate reproduction of the thermal processes micrometeorites had suffered, an extraordinary quick heating and quenching on tiny particles should be accomplished. In this study, we constructed a fine particle free fall apparatus in a high temperature furnace to carry out crystallization experiments with controlled rapid heating and quenching. To assess the apparatus, we carried out rapid heating/quenching experiments with volcanic ash from Sakurajima volcano, which is abundant and contains various minerals and groundmass including magnetite crystals.

\section{FINE PARTICLE FREE FALL APPARATUS}

In experimental Earth and planetary sciences, it is always essential problem to fill the gap between natural and experimental systems that can be practically handled. Estimations of time scale for chondrule formation processes are compiled by Desch et al. (2012) based on numerous experimental and theoretical studies. The cooling rate of the chondrule formation falls within the range of 1 to $10^{4}$ $\mathrm{K} / \mathrm{h}$. Sample size and cooling rate for chondrule formation processes are in the range for precise reproduction in laboratory experiments using high temperature furnaces with the practical handling methods. With silicate starting materials of several millimeters in diameter, reproduction experiments for chondrules have been successful with various methods (e.g., Tsuchiyama et al., 1980, 2004; Lofgren and Russell, 1986; Lofgren and Lanier, 1990; Cohen et al., 2004; Fox and Hewins, 2005; Nagashima et al., 2006; Nettles et al., 2006; Zieg and Lofgren, 2006).

However, time scale to reproduce thermal history of micrometeorites is much shorter than that of the chondrule formation. Cooling rate of micrometeorite may exceed $10^{3} \mathrm{~K} / \mathrm{s}$. And typical size of micrometeorites is merely several tenth millimeters in diameter. It is impossible to keep such tiny samples without interference to crystallization processes with sample holding structures contacting directly to the sample. In addition, the direct sample holding structures prevent rapid quench because of its much larger thermal capacity than that of the tiny sample. Previous attempt to reproduce micrometeorite have been carried out for fragments of Orgueil or Murchison meteorite $100-400 \mu \mathrm{m}$ in size on alumina tube (Greshake et al., 1998) or in tiny crucible made with Pt wire (Toppani et al., 2001; Toppani and Libourel, 2003). Quench processes of their experiments were performed by pulling out the samples to the air. They noted that the 
cooling rates of their experiments are unexpectedly slower than those of micrometeorites.

A non-contact sample holding method should have possibility to solve this problem. In the terrestrial gravity field, it is impossible to keep stable position of the sample in the furnace without some sample holding structure. Free falling particles undergo, however, air drug by viscosity of the ambient gas, and reach constant terminal velocity. If time scale of passing particles through a vertical furnace is concordant to continuous thermal radiation equilibrium with temperature distribution of the furnace, it is possible to control thermal history of the samples for rapid heating and quenching by control on falling velocity.

We carried out feasibility study to control the falling velocity and thermal history of sample particles through the high temperature vertical furnace (NIKKATO TS4806) quantitatively. The priority of the objective is to reproduce rapid quenching profile with heating, stable and quenching durations for approximately $1 \mathrm{~s}$. The effective terminal velocity of silicate particles is controlled by diameter of the particles and viscosity of gas in the furnace tube. The furnace is equipped with mass flow controllers (KOFLOC 3810DS) for $\mathrm{H}_{2}, \mathrm{CO}_{2}$ and $\mathrm{Ar}$ to control oxygen fugacity and total gas flow rate providing upward flow in the furnace tube.

We applied particle with $100 \mu \mathrm{m}$ in diameter, typical size of micrometeorites, and viscosity of $\mathrm{H}_{2}, \mathrm{CO}_{2}$ and $\mathrm{Ar}$ mixture gas at temperature above $1200{ }^{\circ} \mathrm{C}$ estimated based on Dawe and Smith (1969), Thakur et al., (1994) and Frank et al., (1996) on the Stokes' law to calculate terminal velocity of particles. Terminal velocity of silicate particles with $100 \mu \mathrm{m}$ in diameter in the static Ar gas at $1200{ }^{\circ} \mathrm{C}$ is approximately $0.18 \mathrm{~m} / \mathrm{s}$. Gas ascent rate at $1200{ }^{\circ} \mathrm{C}$ is approximately $0.11 \mathrm{~m} / \mathrm{s}$ in the furnace tube of $30 \mathrm{~mm}$ in inner diameter when total gas flow rate is approximately $1 \mathrm{l} / \mathrm{min}$ at the standard condition. The terminal velocity of the particles with $100 \mu \mathrm{m}$ in diameter, therefore, is reduced to approximately $0.07 \mathrm{~m} / \mathrm{s}$.

In the temperature range above $1000{ }^{\circ} \mathrm{C}$, target temperature of this study, heat transportation is dominated by radiation. The calculation following the StefanBoltzmann law with the values of specific area, specific gravity and specific heat of the silicate particle with 100 $\mu \mathrm{m}$ in diameter shows that the particle can reach thermal equilibrium within the order of 0.1 seconds in this temperature range. This means the sample particle can follow continuously the temperature distribution of the furnace if it takes more than a few second to pass through the furnace.

Constant dropping of the fine particles into the furnace tube can be implemented by a silica glass tube with an orifice at the bottom approximately $0.5 \mathrm{~mm}$ in diameter. Sample particles pass through the orifice from the silica glass tube like hourglass sands. The tip of the silica glass tube is set $13.5 \mathrm{~cm}$ from the top of the furnace tube, approximately $14 \mathrm{~cm}$ above the hot spot of the furnace to reduce scattered particles hitting the furnace tube wall. An alumina crucible $25 \mathrm{~mm}$ in outer diameter is set at the bottom of the furnace tube to retrieve the quenched samples. The schematic drawing of the experimental configuration is shown in Figure 1.

The vertical temperature profile of the furnace with Ar gas flow of $1.0 \mathrm{l} / \mathrm{min}$ at the standard condition is shown in Figure 2 when temperature of heating elements of the furnace is set for $1600^{\circ} \mathrm{C}$. Temperature is measured with type $\mathrm{R}$ thermocouples. Length of the highest temperature zone of the vertical furnace for our experiment is

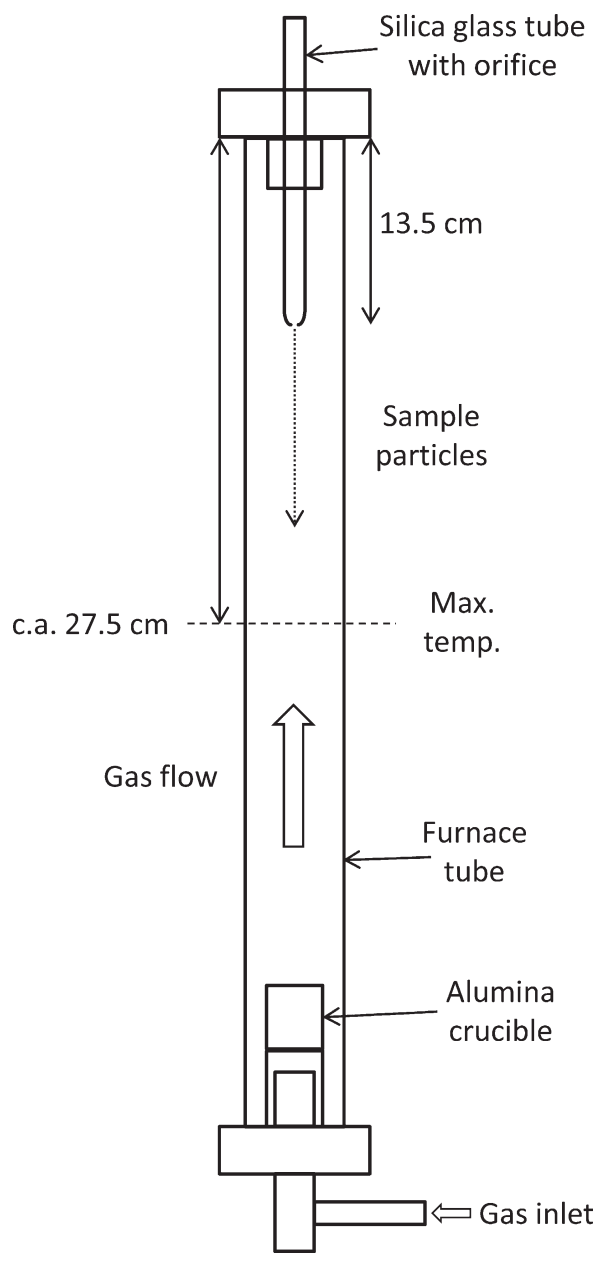

Figure 1. Schematic illustration of the furnace tube of the fine particle free fall apparatus. The alumina furnace tube of $3 \mathrm{~cm}$ in inner diameter is heated by six lanthanum chromate heating elements. Outer and inner diameter of silica glass tube for the sample supply is $5 \mathrm{~mm}$ and $3 \mathrm{~mm}$, respectively. Hydrogen, $\mathrm{CO}_{2}$ and $\mathrm{Ar}$ gases for oxygen fugacity and total volume control are regulated by mass flow controllers with a digital mass flow meter and a needle valve, and mixed before the gas inlet. 


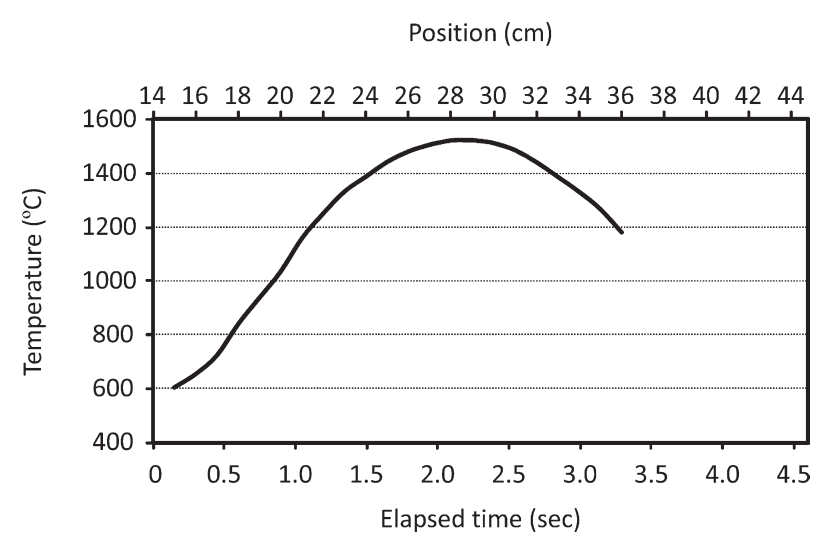

Figure 2. Temperature distribution with respect to the distance from top of the furnace tube. Lower horizontal axis shows elapsed time from the orifice of the silica tube for the sample particles of $100 \mu \mathrm{m}$ in diameter.

approximately $5 \mathrm{~cm}$.

Velocity of the sample particles dropped from the orifice of the silica glass tube is calculated by the equation of motion with gravity and drag forces led by the Stokes' law. Particles of $100 \mu \mathrm{m}$ in diameter reach constant velocity of c.a. $6.7 \mathrm{~cm} / \mathrm{sec}$ within 0.2 second and $1 \mathrm{~cm}$ falling after passing through the orifice. Figure 2 shows correlations between elapsed time of falling, temperature and sample position from the top of the furnace tube for particles with constant falling velocity. Sample particles heated from approximately $500{ }^{\circ} \mathrm{C}$ to over $1400{ }^{\circ} \mathrm{C}$ within $2 \mathrm{~s}$, and kept over $1400{ }^{\circ} \mathrm{C}$ approximately $1 \mathrm{~s}$, and quenched by approximately $500{ }^{\circ} \mathrm{C} / \mathrm{s}$, or equivalently $2 \times 10^{6} \mathrm{~K} / \mathrm{h}$. The maximum temperature is approximately $1520{ }^{\circ} \mathrm{C}$ in this configuration. Time scale of thermal history varies depending on the particle size. Larger particles fall faster than smaller particles, and experience shorter heating duration and more rapid quenching. The evaluation described above shows that the heating and quenching experiment of free fall fine particles in the vertical furnace with controlled gas flow has intrinsic advantage to reproduce thermal history and crystallization processes unique to micrometeorites with extraordinary rapid cooling rate from high temperature.

\section{EXPERIMENTAL}

Starting material is prepared from volcanic ash sampled from Sakurajima volcano, Kagoshima, Japan. The particles for the experiments are sieved fraction between 60 $\mu \mathrm{m}$ and $160 \mu \mathrm{m}$ in diameter. Particles show irregular and angular shape under a stereoscopic microscope (Fig. 3a). Observation with a field-emission scanning electron microscope (FE-SEM, JEOL JSM-7001F) also shows angular shape of the starting material particles (Fig. 3b). Pol-
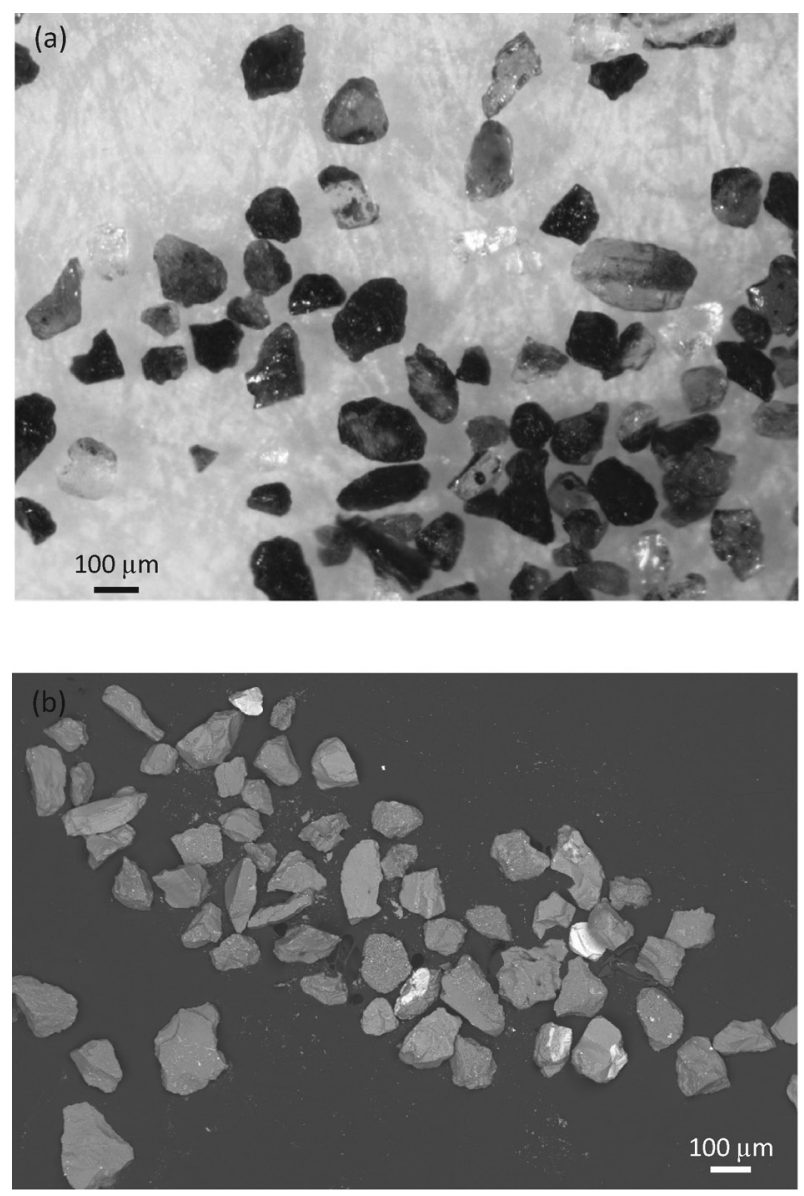

Figure 3. (a) Optical stereographic microscope photograph of Sakurajima volcanic ash particles. Plagioclase dominated particles can be seen as clear and transparent grains. While pyroxene phenocryst shows dark green and groundmass glass can be seen as glassy black under the microscope. Magnetite dominated particles show opaque black. (b) Backscattered electron image of the volcanic ash particles. All particles have angular shape with sharp edges. Magnetite can be seen as white grains.

ished section of the particles shows that the particles are fragments of typical pyroxene andesite with plagioclase and pyroxene phenocrysts and minor magnetite crystals in fine crystalline and glassy groundmass (Figs. $4 \mathrm{a}$ and $4 \mathrm{~b}$ ). Each particle contains plagioclase, pyroxene, magnetite and groundmass glass in various proportions. Some particles have quite high volume fraction of magnetite (Fig. 4c), and particles with vesicles also occur (Fig. 4d).

Approximately 15-50 mg of volcanic ash particles are used for a batch of the experiment. The weight ratio of retrieved run products to the starting material stands approximately $60-75 \%$. Typical gas flow rates in standard condition are as follows, $\mathrm{H}_{2} ; 1.0 \mathrm{~cm}^{3} / \mathrm{min}, \mathrm{CO}_{2} ; 269 \mathrm{~cm}^{3} /$ $\mathrm{min}, \mathrm{Ar} ; 0.70 \mathrm{l} / \mathrm{min}$. Oxygen fugacity determined by $\mathrm{H}_{2} /$ $\mathrm{CO}_{2}$ ratio (Prunier and Hewitt, 1981) is set for the FMQ buffer curve extrapolated based on the formula compiled in Frost (1991) + $1.5 \log$ unit. Because the dependence of 

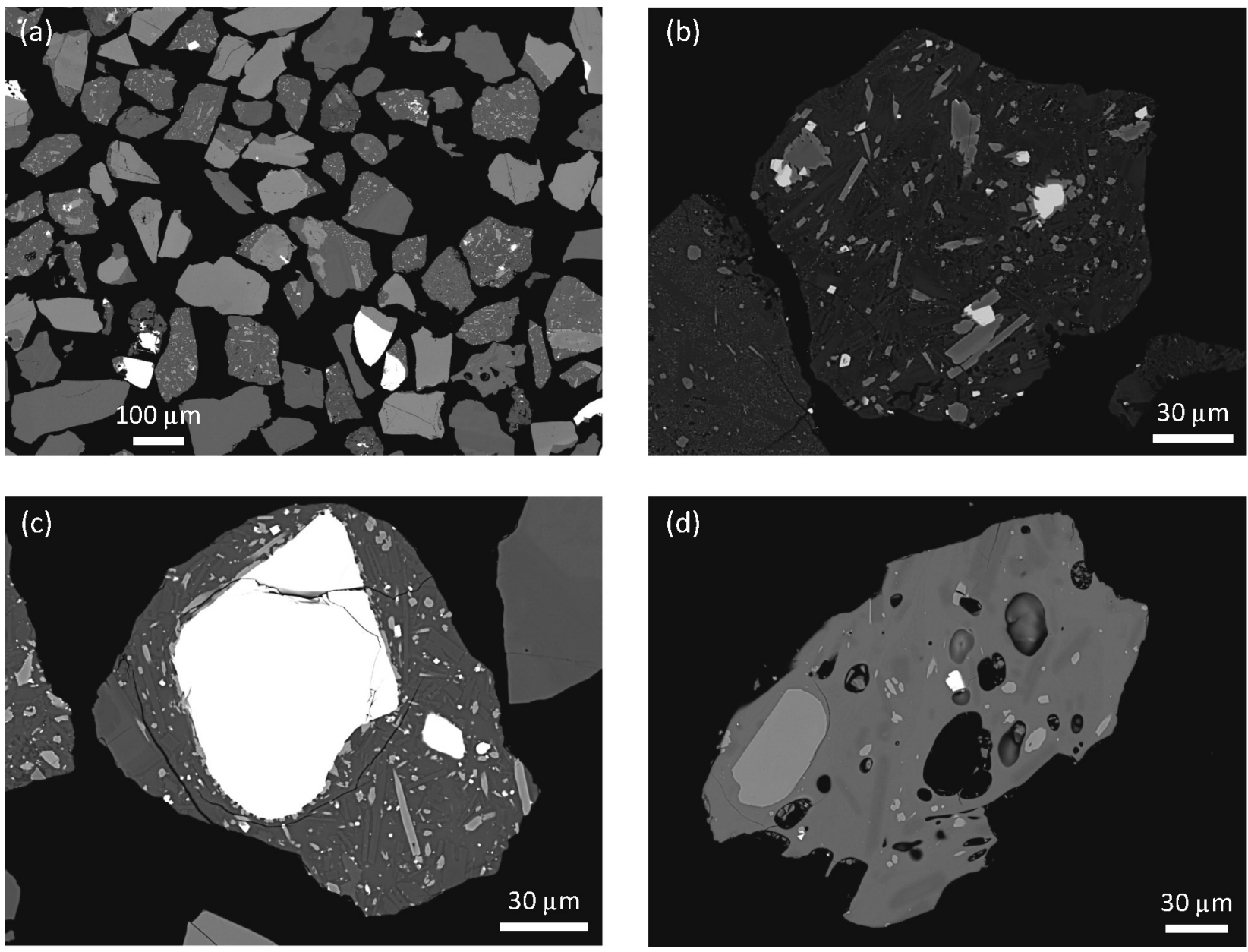

Figure 4. (a) Backscattered electron image of the volcanic ash particles polished section. Volcanic ash particles consist of pyroxene, plagioclase, groundmass, magnetite or various mixtures of these minerals. (b) A particle of groundmass fragment. (c) A particle with magnetite crystal in groundmass. (d) A particle consisting a pyroxene phenocryst and rounded vesicles. Outer shape of the grain shows pits and projections.

oxygen fugacity on temperature for $\mathrm{H}_{2} / \mathrm{CO}_{2}$ gas mixture and FMQ buffer curve are almost parallel between 1100 ${ }^{\circ} \mathrm{C}$ and $1500{ }^{\circ} \mathrm{C}$, relative oxygen fugacity of the gas mixture to FMQ buffer curve in the furnace tube is almost constant irrespective of the sample position in the furnace.

Retrieved samples from the alumina crucible at the bottom of the furnace tube are observed with stereoscopic microscope. Selected particles are fixed on conductive adhesive tape and observed by the FE-SEM. After observation of outer shape of the run products, particles are embedded in an acrylic resin and polished. Cross section of the run products are observed by the FE-SEM and analyzed by an EDS (Oxford INCA system).

\section{RESULTS}

After the experiments, more than half of the volcanic ash particles melted very well to shape spherical form (Figs. $5 \mathrm{a}$ and $5 \mathrm{~b}$ ). The presence of well melted silicate particles shows that the maximum temperature estimation described in the previous section is proved. However, some particles are not completely melted but obviously partially melted and lost angular shape. Dispersion in falling velocity should be caused by deviation of sample particle size and turbulent flow in the furnace tube.

Groundmass glass and plagioclase particles formed quite clear glass spherules while mafic minerals dominated particles show black spherules under the stereoscopic microscope (Fig. 5a). Surface of the spherical particles is smooth and reflective due to quenched glass. Figure 6 shows completely melted particles with perfectly spherical shape due to surface tension of silicate melt in spite of very short duration of melting. Heterogeneity in the melt arising from petrologic texture of the volcanic ash particle, however, survive and can be seen as indistinct contrast on the spherule surface in backscattered electron images (Figs. 6b and 6c). Vesicles in the volcanic ash particles are not completely expelled from the melt spher- 

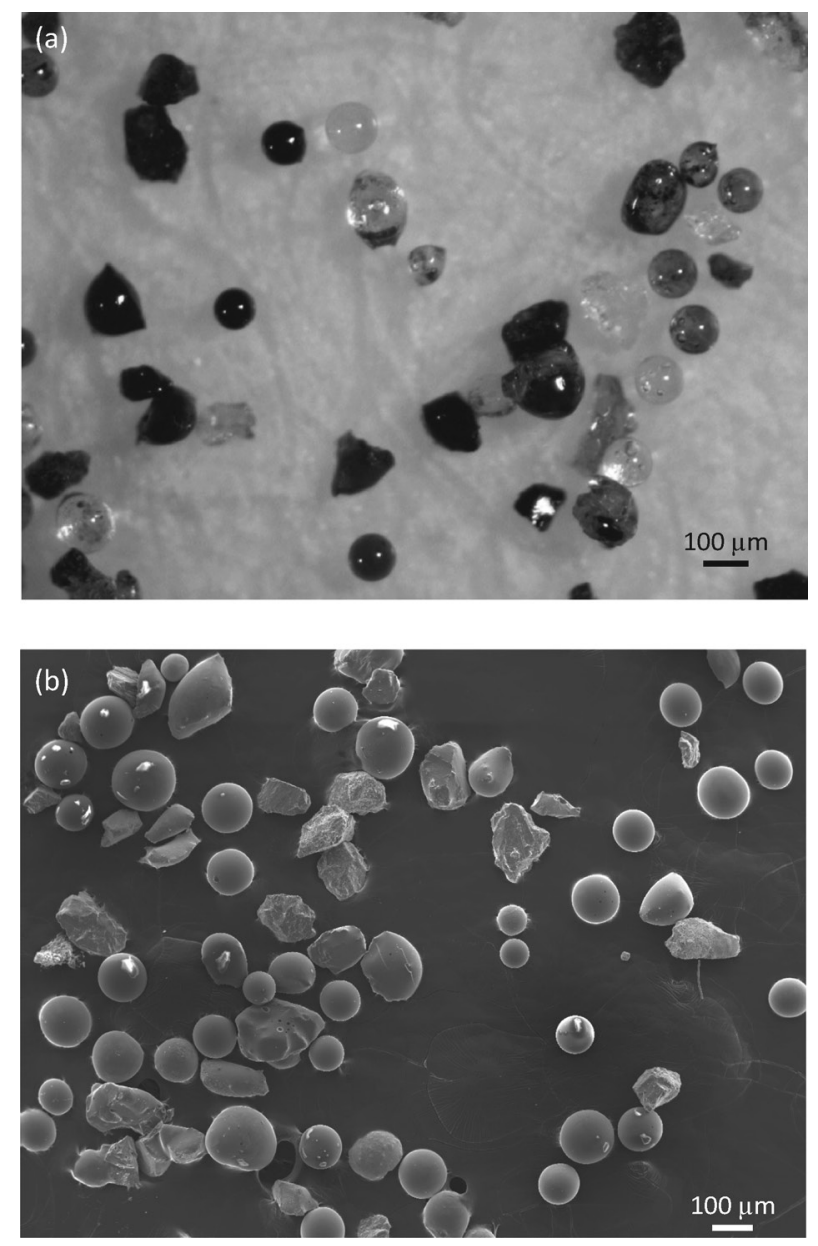

Figure 5. (a) Optical stereographic microscope photograph of retrieved run products particles. We can see perfectly spherical glass grains of clear, light-colored or black. The most of grains other than spherical particles also show glassy surface due to quench glass covering the surface. (b) Secondary electron image of the run product particles. Much of the particles show smooth surface as observed with optical microscope.

ule (Fig. 6b).

Relict minerals affected variously on outer shape of the run product particles depending on their volume fraction to melt. Run product particles show various outer shapes from smoothly surfaced irregular shape, domeshaped to spherical form (Figs. 5b and 6c). However, there was no sign of the impact at the sample retrieval from the shape of spherules. This means that melted spherules quenched sufficiently following the temperature gradient of the lower half of the furnace tube as expected, and terminal velocity of spherules is slow enough to withstand impact.

Under the FE-SEM observations, we can see quite characteristic texture in which dendritic magnetite cover almost whole surface of the spherule (Fig. 7). Spherical shape suggests that the spherule melted almost completely at the highest temperature section of the furnace. Then
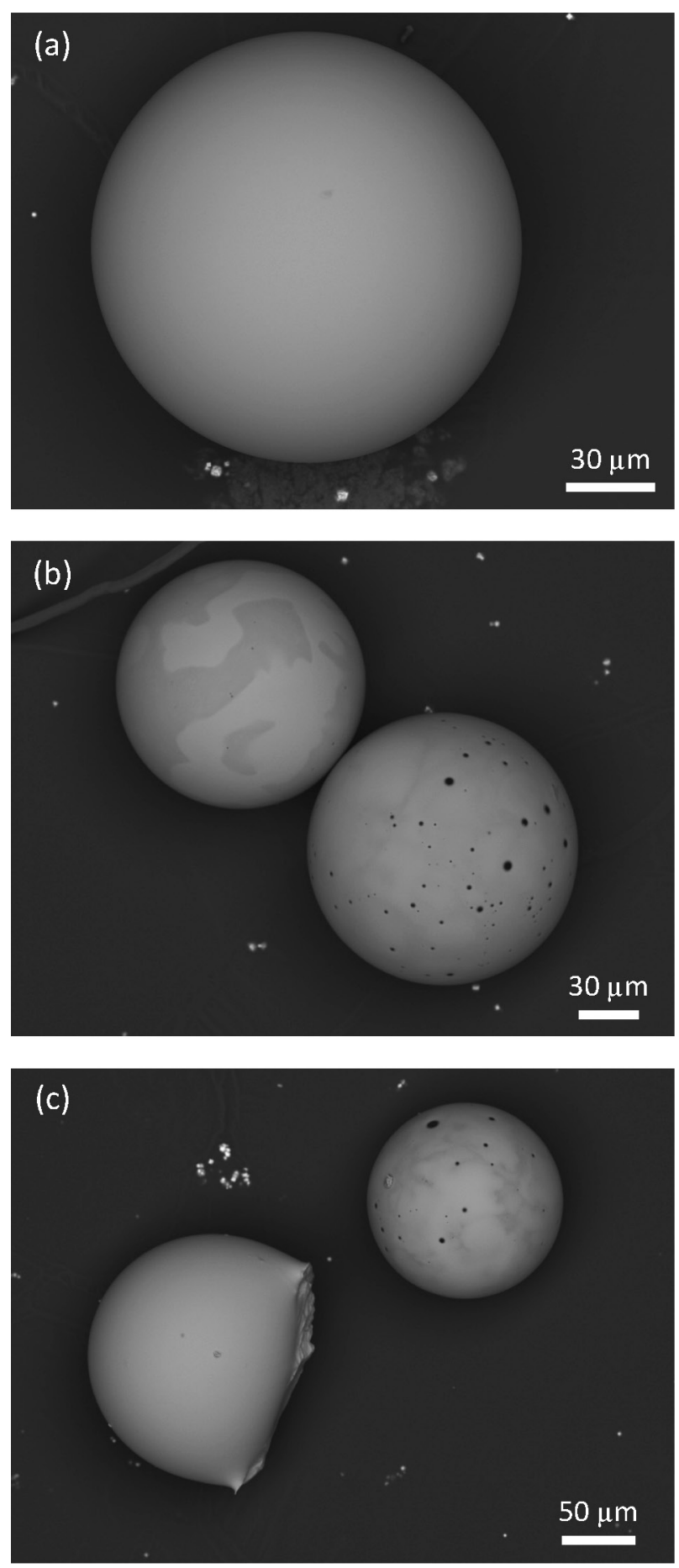

Figure 6. (a) Backscattered electron image of the perfectly spherical run product. This spherule is homogeneous glass. (b) Backscattered electron image of the run product spherules. The upper left spherule shows heterogeneity in melt droplet. On the surface of the lower right spherule, plural bubbles derived from vesicles in the volcanic ash particles can be seen. (c) Backscattered electron image of the run product spherules with small bubbles and melt heterogeneity (upper right) and dome-like shape (lower left). 

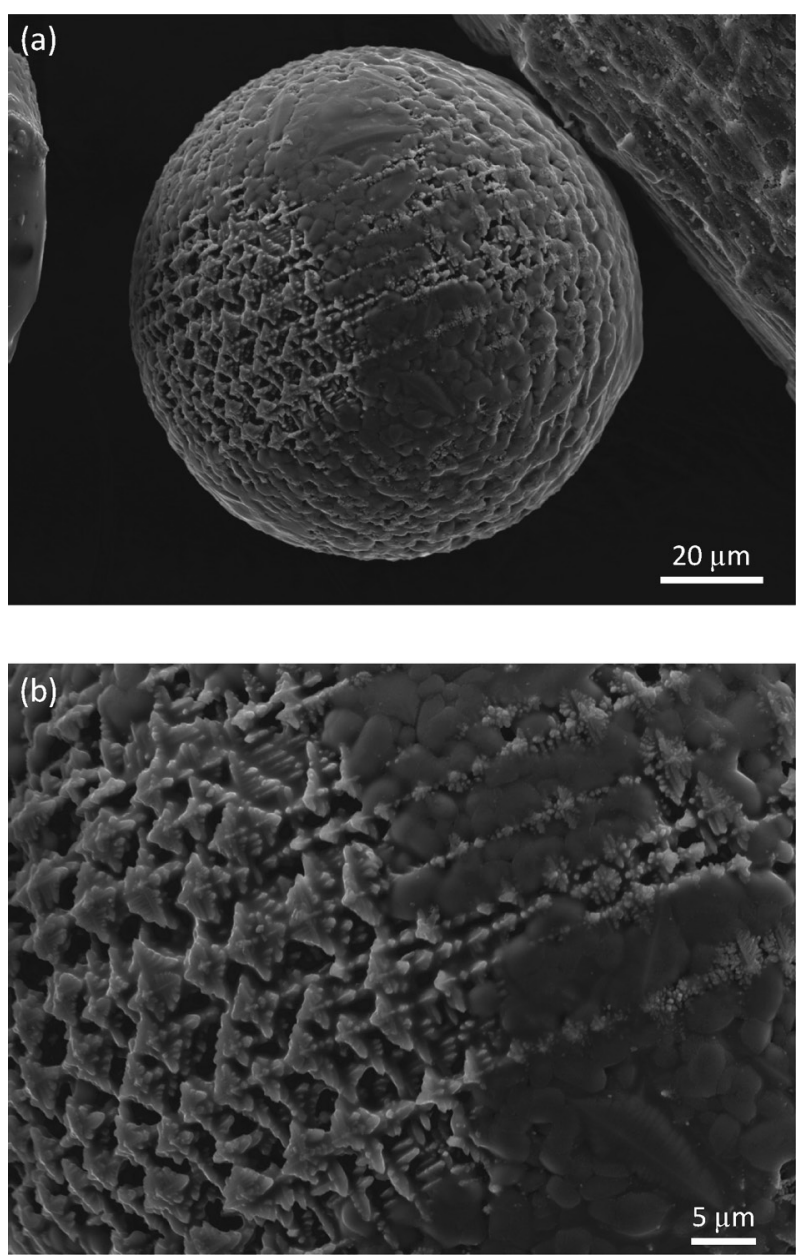

Figure 7. Secondary electron image of a spherule with quite characteristic texture. (a) We can see the spherule has lattice structure of dendritic crystals on the whole of the spherule despite the completely spherical outer shape. On the surface of the spherule, linear structures like longitude and latitude lines on a globe. (b) SEI of the spherule surface. Parallel rows of dendritic crystals like micron scale winged creatures can be seen.

dendritic magnetite crystals grow with some regularity over the whole spherule. Parallel structure of the dendrite crystals looks like a terrestrial globe. The surface of the spherules is covered with uniform shaped structures (Fig. $7 b)$. Melt fraction fills and covers partially interstices between dendritic crystals and its twigs.

Magnetite dendrite crystals with particular crystallographic orientation to the spherule surface also occur in the more melt-rich, less-crystalline spherules (Fig. 8). Magnetite dendrite crystallizes in iron-rich melt fraction (Figs. 8a and 8b). Magnetite dendrite shows the quite characteristic texture depending on three-dimensional relation between dendritic crystals and surface of the spherule. The surface texture of the spherules shows that the crystallographic orientation of magnetite dendrites is regulated in the quite large area, eventually to the whole spherule, through the quenching process of the melted spherules.
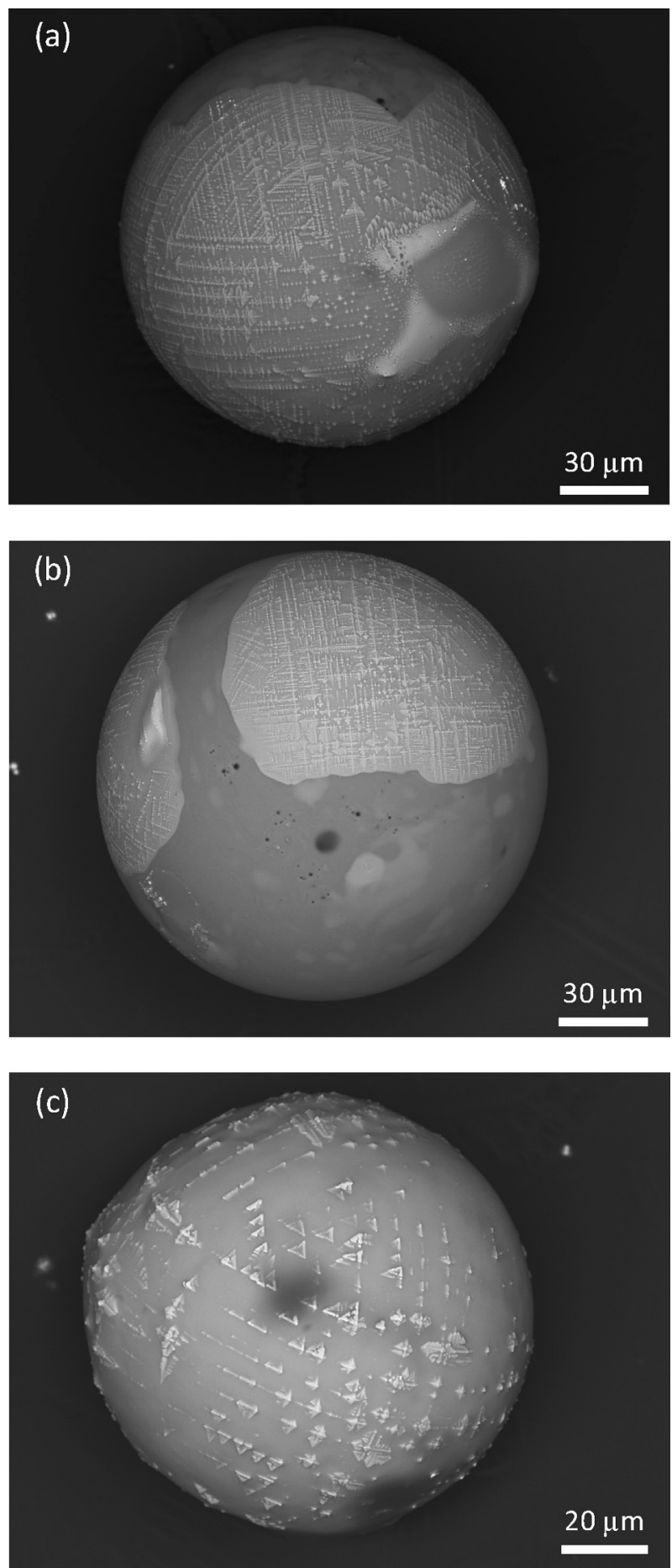

Figure 8. (a) and (b) Backscattered electron images of spherules consist of heterogeneous melt. In the iron-rich melt, dendritic crystals show parallel structure on the surface. (c) More meltrich, poor-crystalline spherule. In the area with crystallographic axis ([100] direction) perpendicular to the surface, daggershaped crystals occur. While in the area with [111] direction perpendicular to the surface, regular triangle crystals can be seen. 

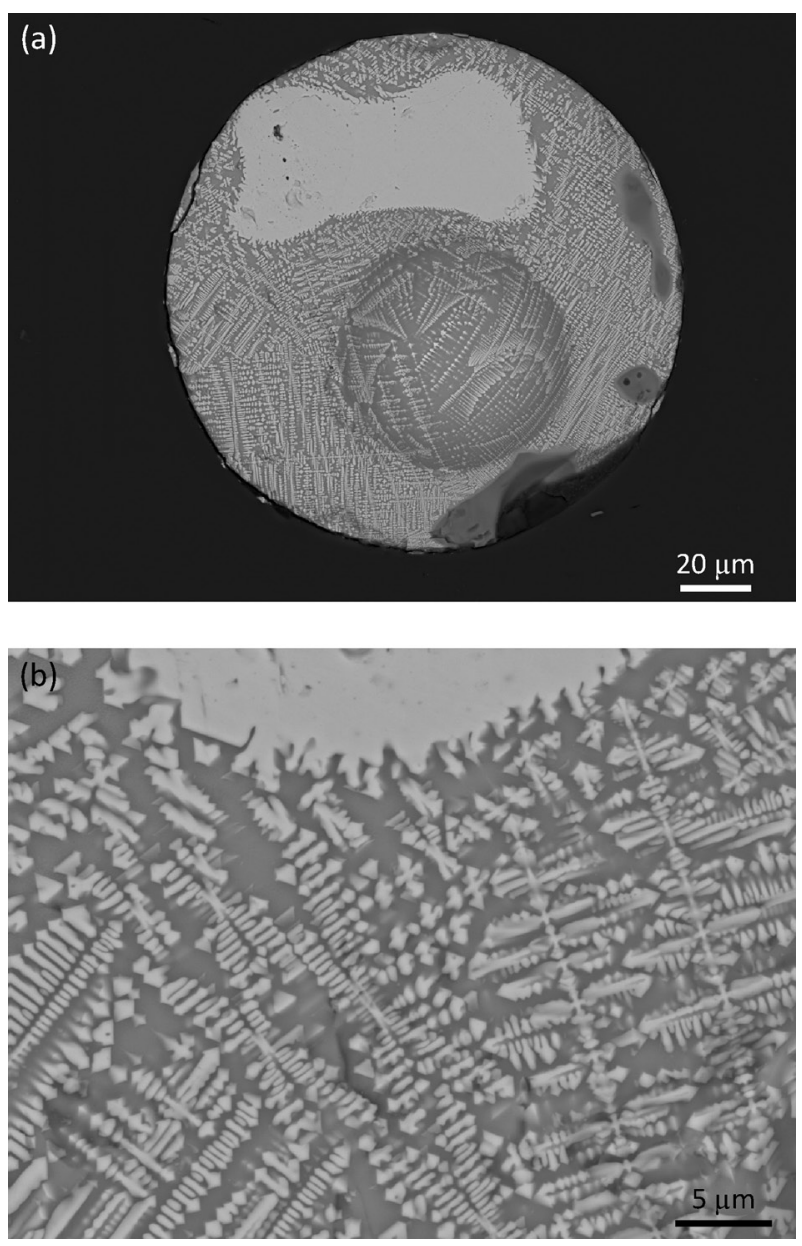

Figure 9. Backscattered electron image of polished section of a spherule with relict magnetite and dendritic crystals. Dendrites elongate more than $50 \mu \mathrm{m}$ in length. Interior of this spherule is divided to several domains with different crystallographic orientation indicated by elongation direction of dendrites.

Polished sections of the spherules are observed by FE-SEM (Figs. 9, 10 and 11). Figure 9 shows the spherule contains a dumbbell-shaped relict magnetite crystal and a spherical void almost half the diameter of the spherule. Magnetite dendritic crystals fill uniformly throughout the melt and appear continuously on the surface of the void. Several domains occupied by dendrites with oriented elongation directions can be seen.

Compositions of magnetite by EDS analysis show slight variations in and between relict grains and quench grown dendrites. Titanium content in the most relict magnetite are $10-14 \mathrm{wt} \%$ as $\mathrm{TiO}_{2}$, and those in the most dendrites are $4-8 \mathrm{wt} \%$. Representative chemical compositions are listed in Table 1. Cations and oxidation state of Fe are calculated on the assumption of magnetite-ulvöspinel solid solution satisfying total 3 cations based on 4 oxygens.

Quench growth of dendritic crystals from surface of the relict magnetite crystal occur in the spherule with melt
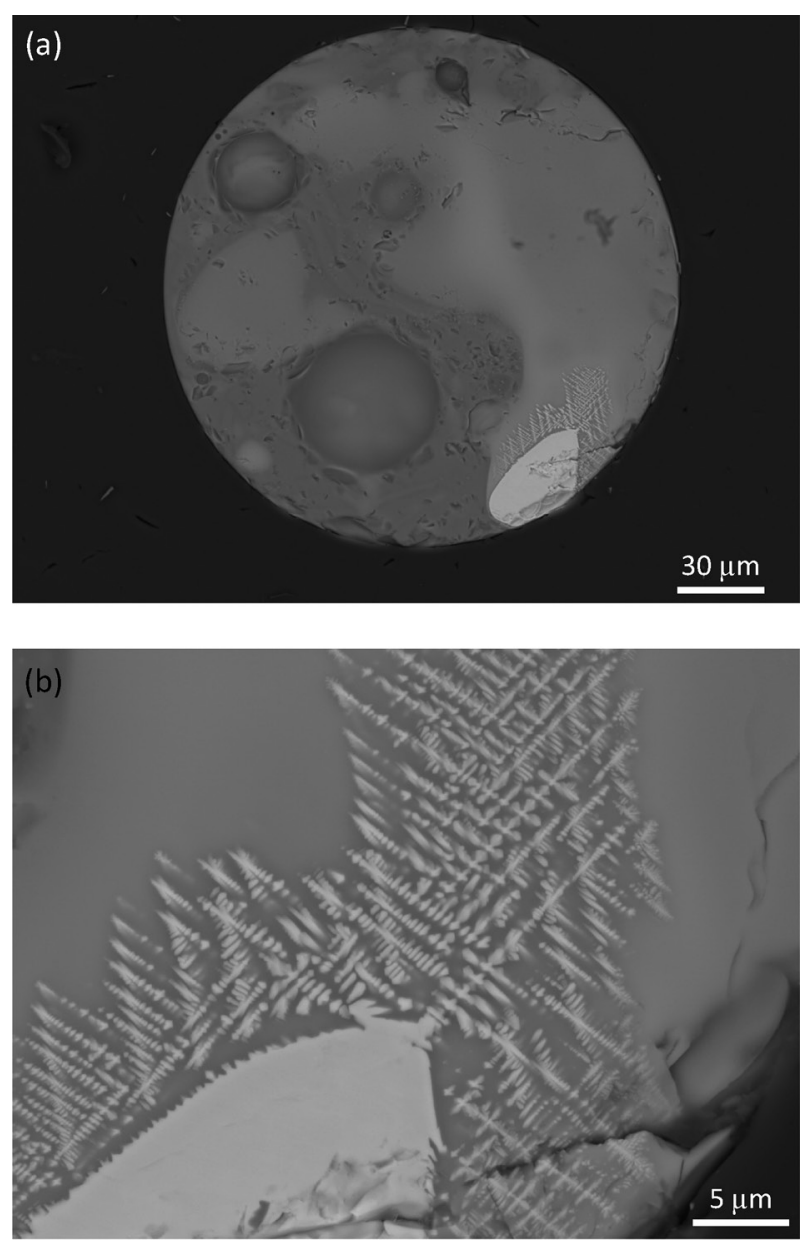

Figure 10. (a) Backscattered electron image of polished section of a spherule with melt heterogeneity and a relict magnetite. (b) The relict magnetite crystal initiate oriented growth of dendrite up to $30 \mu \mathrm{m}$ in length.

heterogeneity (Fig. 10). Dendrites grow from the relict mineral up to $30 \mu \mathrm{m}$. Magnetite dendrites shown in Figure $10 \mathrm{~b}$ elongate with uniform crystallographic orientation. The very limited connection from the relict crystal can be seen at the tip of the crystal. However, we cannot see any connected structure between the most part of the relict magnetite surface and quenched dendrites. Tiny crystals with identical orientation at the tip of the dendrites show that connections of dendrites are limited to quite small area.

Uniformity in the crystal habit and orientation can be also seen in the magnetite dominated and less melted particle (Fig. 11). Dagger-shaped magnetite crystals with almost uniform orientation occur in the quenched melt on the surface of the relict magnetite. In this particle, quench overgrown rim of the relict crystal and crystals in the melt are completely separated. 

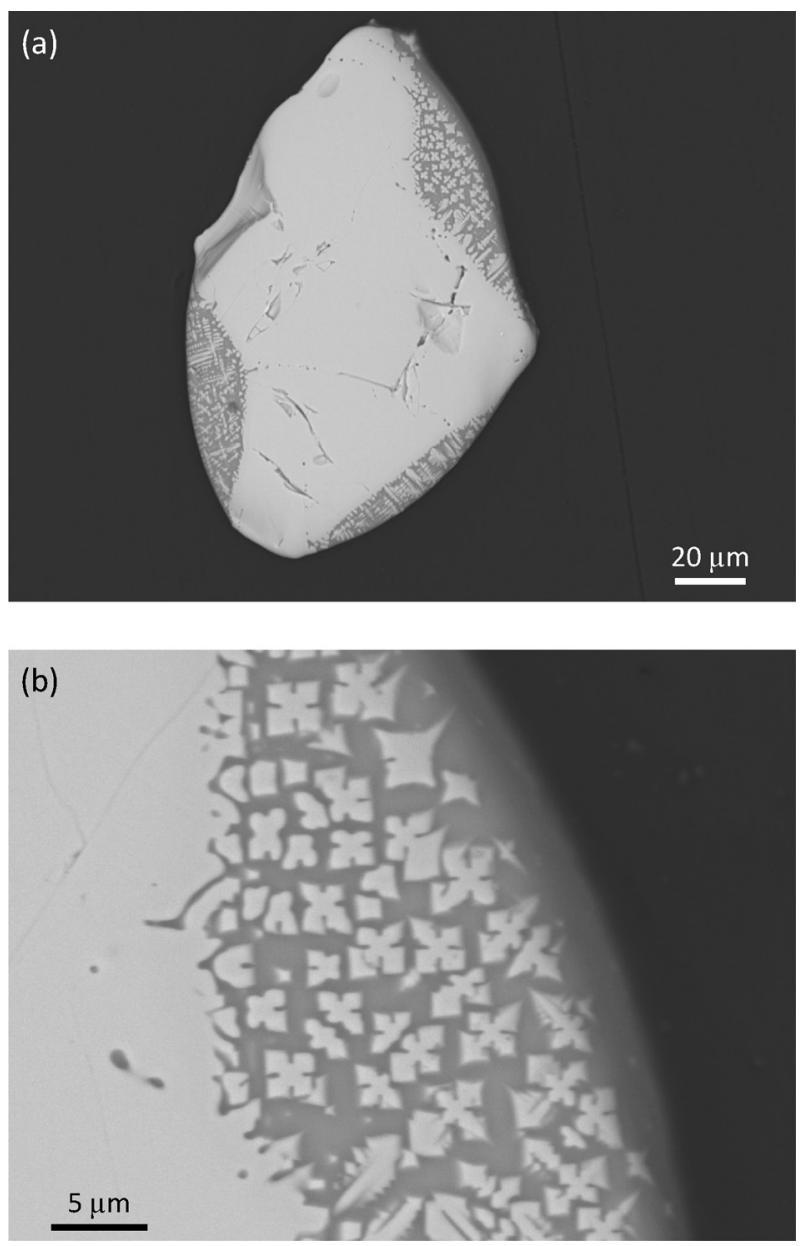

Figure 11. (a) Backscattered electron image of polished section of a less-melted particle. The most of the particle is relict magnetite. (b) The arrangement of dagger-shaped crystals shows that the crystallographic orientation of the crystals is almost identical.

\section{DISCUSSION}

The fine particle free-fall apparatus developed by this study made melting and extraordinary rapid quenching of fine particles with approximately $100 \mu \mathrm{m}$ in diameter implementable. The quench rate of melt particles accomplished to approximately $500^{\circ} \mathrm{C} / \mathrm{s}$, or equivalently $2 \times 10^{6}$ $\mathrm{K} / \mathrm{h}$. We can see the crystallization texture formed by the extraordinary rapid quenching in the run products. Heterogeneity reserved in the spherules shows that the viscosity of the melt is not low enough to mechanically mix in melted period. And diffusion rate is also slow enough to preserve heterogeneity in $10 \mu \mathrm{m}$ scale in the rapid cooling processes.

Magnetite dendrite can grow with uniform orientation in quite fast quenching process. Oriented arrangement of dendritic or skeletal magnetite is quite common in the run products of this study. Extremely limited connections in dendrite stems can align uniform orientation
Table 1 Representative chemical compositions of a relict magnetite and the quench grown dendrite

\begin{tabular}{|c|c|c|}
\hline Oxide wt \% & Relict & Dendrite \\
\hline $\mathrm{TiO}_{2}$ & 11.4 & 6.2 \\
\hline $\mathrm{MgO}$ & 1.8 & 2.3 \\
\hline $\mathrm{FeO}$ & 38.7 & 33.3 \\
\hline $\mathrm{Fe}_{2} \mathrm{O}_{3}$ & 42.7 & 51.7 \\
\hline $\mathrm{Al}_{2} \mathrm{O}_{3}$ & 3.0 & 4.2 \\
\hline Total & 97.6 & 97.7 \\
\hline \multicolumn{3}{|c|}{ Cations on 4 oxygens } \\
\hline $\mathrm{Ti}$ & 0.326 & 0.176 \\
\hline $\mathrm{Mg}$ & 0.100 & 0.129 \\
\hline $\mathrm{Fe}^{2+}$ & 1.226 & 1.047 \\
\hline $\mathrm{Fe}^{3+}$ & 1.215 & 1.461 \\
\hline $\mathrm{Al}$ & 0.133 & 0.187 \\
\hline Total & 3 & 3 \\
\hline
\end{tabular}

of dendrites. In some case, dendrites with lattice structure can fill the whole volume of tiny spherules. Evenly spaced limbs and parallel dendrites suggest that periodical acceleration of growth may be essential in the fast quenching melt spherule.

A single orientation of lattice-like structure of magnetite in a whole spherule show parallel or regular triangle appearance depending on the crystallographic relation of the lattice indices perpendicular to the local spherule surface. Because of isometric unit cell of magnetite, parallel structure can be seen corresponding to edges in octahedron single crystal (Figs. 7 and 8). On the other hand, regular triangle textures on the spherules correspond to planes of the octahedron with (111) lattice index. Dendritic magnetites in Figure 9b clearly show multiple nucleation with different orientations. Even in this case, we think that the dendritic crystals show quite a few orientations, and it means nucleation density is remarkably low and the growth rate of dendrite is quite fast.

Lattice-like structure occupying the whole spherule and separated distribution of skeletal crystals with the uniform orientation suggest that the interactions regulating crystallographic direction of nuclei at the crystallization may work in the rapid quenching of the tiny melt spherules. Magnetite crystallizes as a liquidus phase at the very beginning of the cooling process of the silicate melt. Distances between stem of the dendrites or core of the skeletal crystals indicate nucleation densities depending on the supercooling degree. In the rapid quenching processes of the tiny spherule of the silicate melt, tendency to shrinkage of melt spherule due to surface tension may bring some kind of strain in the silicate melt structure in 
atomic scale. This strain may fix crystallographic direction of nuclei. The initial nucleation in the melt spherule may regulate whole area of the spherule.

Relict magnetite in the melt can play the role of a seed crystal in cooling process. Crystallographic direction of the overgrown rim on the surface of the relict crystal is generally concordant to that of the seed crystal. Figure 11 shows that the concordance of the orientation can be seen even in the separated crystals from the surface of the relict minerals. Skeltal magnetite crystals adjacent but separated each other have quite close orientations. This texture suggests that the periodical nucleation with aligned orientation occurred.

Dendritic or skeletal form in dagger-shape of magnetite (Figs. 7-11) is quite characteristic in cooling processes of high temperature melt in various occurrences. However, ordered arrangements of dendrites or skeletal crystals have never been reported from the terrestrial or meteoritical occurrences. Randomly oriented dendritic magnetite crystals occur in the interstices glass of quenched melt (e.g., Szramek et al., 2010).

Nucleation density and the ultimate crystal size and habit at the end of the cooling processes can provide the most important information to understand thermal history of various situations. In the chondrule formation processes, crystallographic constrain at crystal growth occur in barred olivine and radial pyroxene chondrules. Barred olivine texture is also reported in cosmic spherules, which are melted micrometeorite (Cordier et al., 2011). The fine particle falling apparatus developed in this study has expanded cooling rate in laboratory experiments up to $2 \times$ $10^{6} \mathrm{~K} / \mathrm{h}$. This is essential to reproduce thermal history of atmospheric heating of micrometeorites.

\section{CONCLUDING REMARKS}

The fine particle falling apparatus developed in this study has expanded cooling rate of silicate melt in laboratory experiments up to $500{ }^{\circ} \mathrm{C} / \mathrm{s}$, or equivalently $2 \times 10^{6} \mathrm{~K} / \mathrm{h}$. This is essential to reproduce thermal history of atmospheric heating of micrometeorites. In the extraordinary rapid quenching processes, extremely characteristic oriented textures of dendritic and skeletal magnetite crystals occur. The comparison of the spherules reproduced by this apparatus and natural micrometeorites can provide essential information to understand thermal histories and cooling processes of micrometeorite. The formation of oriented dendrites or skeletal magnetite crystals grown in the silicate melt may be indicative of a relationship between nucleation and fast growth of oriented dendrites in the rapid-quenching process.

\section{ACKNOWLEDGMENTS}

The authors gratefully acknowledge to two anonymous referees for their constructive reviews and detailed comments on the manuscript. This study was partially supported by a Grant-in-Aid for Scientific Research from the Japan Society for the Promotion of Science (No. 21540440). The authors are grateful to Mr. Y. Nishida for Sakurajima volcanic ash samples.

\section{REFERENCES}

Cohen, B.A., Hewins, R.H. and Alexander, C.M.O. (2004) The formation of chondrules by open-system melting of nebular condensates. Geochimica et Cosmochimica Acta, 68, 16611675.

Cordier, C., van Ginneken, M. and Folco, L. (2011) Nickel abundance in stony cosmic spherules: Constraining precursor material and formation mechanisms. Meteoritics and Planetary Science, 46, 1110-1132.

Dawe, R.A. and Smith, E.B. (1969) Viscosity of argon at high temperatures. Science, 163, 675-676.

Desch, S.J., Morris, M.A., Connolly Jr., H.C. and Boss, A.P. (2012) The importance of experiments: Constraints on chondrule formation models. Meteoritics and Planetary Science, 47, 1139-1156.

Fayek, M., Anovitz, L.M., Allard, L.F. and Hull, S. (2012) Framboidal iron oxide: Chondrite-like material from the black mat, Murray Springs, Arizona. Earth and Planetary Science Letters, 319-320, 251-258.

Fox, G.E. and Hewins, R.H. (2005) Chondrule reheating experiments and relict olivine. Geochimica et Cosmochimica Acta, 69, 2441-2449.

Frank, M.J.W., Kuipers, J.A.M. and van Swaaij, W.P.M. (1996) Diffusion coefficients and viscosities of $\mathrm{CO}_{2}+\mathrm{H}_{2} \mathrm{O}, \mathrm{CO}_{2}+$ $\mathrm{CH}_{3} \mathrm{OH}, \mathrm{NH}_{3}+\mathrm{H}_{2} \mathrm{O}$, and $\mathrm{NH}_{3}+\mathrm{CH}_{3} \mathrm{OH}$ liquid mixtures. Journal of Chemical Engineering Data, 41, 297-302.

Frost, B.R. (1991) Introduction to oxygen fugacity and its petrologic importance. In Oxide Minerals (Lindsley, D.H. Ed.). pp. 509, Reviews in Mineralogy 25, Mineralogical Society of America, Washington, D.C., 1-10.

Genge, M.J. (2006) Igneous rims on micrometeorites. Geochimica et Cosmochimica Acta, 70, 2603-2621.

Genge, M.J. (2008) Micrometeorites and their implications for meteors. Earth, Moon and Planets, 102, 525-535.

Grapes, R.H. and Müller-Sigmund, H. (2010) Lightning-strike fusion of gabbro and formation of magnetite-bearing fulgurite, Cornone di Blumone, Adamello, Western Alps, Italy. Mineralogy and Petrology, 99, 67-74.

Greshake, A., Klöck, W., Arndt, P., Maetz, M., Flynn, G.J., Bajt, S. and Bischoff, A. (1998) Heating experiments simulating atmospheric entry heating of micrometeorites: Clues to their parent body sources. Meteoritics and Planetary Science, 33, 267-290.

Haggerty, S.E. (1991) Oxide textures - A mini-atlas. In Oxide Minerals (Lindsley, D.H. Ed.). pp. 509, Reviews in Mineralogy 25, Mineralogical Society of America, Washington, D.C., 129-220.

Kleinmann, B. (1969) Magnetite bearing spherules in tektites. Geochimica et Cosmochimica Acta, 33, 1113-1116. 
Korchagin, O.A., Tsel'movich, V.A., Pospelov, I.I. and Bian, Q. (2010) Cosmic magnetite microspherules and metallic particles near the Permian-Triassic boundary in a global stratotype section and point (Stratum 27, Meishan, China). Doklady Earth Sciences, 432, Part 1, 631-637.

Lofgren, G. and Russell, W.J. (1986) Dynamic crystallization of chondrule melts of porphyritic and radial pyroxene composition. Geochimica et Cosmochimica Acta, 50, 1715-1726.

Lofgren, G. and Lanier, A.B. (1990) Dynamic crystallization study of barred olivine chondrules. Geochimica et Cosmochimica Acta, 54, 3537-3551.

Longo, M., McCammon, C.A. and Jacobsen, S.D. (2011) Microanalysis of the iron oxidation state in $(\mathrm{Mg}, \mathrm{Fe}) \mathrm{O}$ and application to the study of microscale processes. Contributions to Mineralogy and Petrology, 162, 1249-1257.

Love, S.G. and Brownlee, D.E. (1993) A direct measurement of the terrestrial mass accretion rate of cosmic dust. Science, 262, 550-553.

Mirsa, S., Newsom, H.E., Shyam Prasad, M., Geissman, J.W., Dube, A. and Sengupta, D. (2009) Geochemical identification of impactor for Lonar crater, India. Meteoritics and Planetary Science, 44, 1001-1018.

Nagashima, K., Tsukamoto, K., Satoh, H., Kobatake, H. and Dold, P. (2006) Reproduction of chondrules from levitated, hypercooled melts. Journal of Crystal Growth, 293, 193-197.

Naslund, H.R. (1984) Supersaturation and crystal growth in the roof-zone of the Skaergaard magma chamber. Contributions to Mineralogy and Petrology, 86, 89-93.

Nettles, J.W., Lofgren, G.E., Carlson, W.D., and McSween Jr., H.Y. (2006) Extent of chondrule melting: Evaluation of experimental textures, nominal grain size, and convolution index. Meteoritics and Planetary Science, 41, 1059-1071.

Prunier Jr., A.R. and Hewitt, D.A. (1981) Calculation of temperature-oxygen fugacity tables for $\mathrm{H}_{2}-\mathrm{CO}_{2}$ gas mixtures at one atmosphere total pressure. Geological Society of America Bulletin, 92(7), Part II, 1039-1068.

Rice, J.M., Dickey Jr., J.S. and Lyons, J.B. (1971) Skeltal crystallization of pseudobrookite. American Mineralogist, 56, 158162.

Robin, E., Swinburne, N.H.M., Froget, L., Rocchia R. and Gayraud, J. (1996) Characteristics and origin of the glass spherules from the Paleocene flood basalt province of western Greenland. Geochimica et Cosmochimica Acta, 60, 815830.

Sautter, V., Barrat, J.A., Jambon, A., Lorand, J.P., Gillet, Ph., Javoy, M., Joron, J.L. and Lesourd, M. (2002) A new Martian meteorite from Morocco: the nakhlite North West Africa 817. Earth and Planetary Science Letters, 195, 223-238.

Szramek, L., Gardner, J.E. and Hort, M. (2010) Cooling-induced crystallization of microlite crystals in two basaltic pumice clasts. American Mineralogist, 95, 503-509.

Thakur, M.L., Jha, S.C., Jha, A.K. and Sulekha Kumari, S. (1994) A Modified formula of the coefficient of viscocity of gases $\mathrm{He}, \mathrm{H}_{2}, \mathrm{Ne}$ and $\mathrm{Ar}$ at high temperatures. Acta Ciencia Indica, Physics, 20, 86-94.

Toppani, A., Libourel, G., Engrand, C. and Maurette, M. (2001) Experimental simulation of atmospheric entry of micrometeorites. Meteoritics and Planetary Science 36, 1377-1396.

Toppani, A. and Libourel, G. (2003) Factors controlling compositions of cosmic spinels: Application to atmospheric entry conditions of meteoritic materials. Geochimica et Cosmochimica Acta, 67, 4621-4638.

Tsuchiyama, A., Nagahara, H. and Kushiro, I. (1980) Experimental reproduction of textures of chondrules. Earth and Planetary Science Letters, 48, 155-165.

Tsuchiyama, A., Osada, Y., Nakano, T. and Uesugi, K. (2004) Experimental reproduction of classic barred olivine chondrules: Open-system behavior of chondrule formation. Geochimica et Cosmochimica Acta, 68, 653-672.

Woltz, S., Hiergeist, R., Görnert, P. and Rüssel, C. (2006) Magnetite nanoparticles prepared by the glass crystallization method and their physical properties. Journal of Magnetism and Magnetic Materials, 298, 7-13.

Zieg, M.J. and Lofgren, G.E. (2006) An experimental investigation of texture evolution during continuous cooling. Journal of Volcanology and Geothermal Research, 154, 74-88.

Manuscript received November 1, 2012

Manuscript accepted March 28, 2013

Published online June 15, 2013

Manuscript handled by Akira Yoshiasa 